\title{
JANOS JEMNITZ
}

\section{LEO FRANKEL}

Après la chute de la Commune de Paris, Frankel se rapprocha de Marx et d'Engels sur le plan des relations personnelles comme sur celui des idées. Il s'opposa alors aux groupements anarchistes, bakouninistes, et se consacra avant tout à la réorganisation ou au renforcement des organisations ouvrières. Il attacha beaucoup d'importance à la lutte pour la conquête ou la défense de la démocratie politique, et à l'encontre du mouvement bakouniniste il pensait dès 1871-72 que les ouvriers devaient d'abord s'emparer du pouvoir politique et s'en servir ensuite pour atteindre leurs objectifs. Ces perspectives politiques étaient liées pour lui à une autre idée fondamentale de Marx: la nécessité de créer un parti politique autonome. ${ }^{1}$

D'autre part il faut noter les efforts de Frankel, jusqu'à sa mort, pour aider et réunir tous les courants du mouvement ouvrier. Il salua en 1876 le premier congrès ouvrier français et prit part dans les années soixante-dix aux tentatives de la résurrection de l'Internationale. Ainsi il participa au Congrès Socialiste International de Gand en 1877. Il tenta d'y démontrer, à la lumière des expériences du passé et du présent, les contradictions des thèses anarchistes, il analysa les tendances historiques de l'évolution de l'économie, afin de mieux faire comprendre la nécessité de l'expropriation socialiste et l'organisation d'une production socialisée élargie. Mais en même temps il rechercha les possibilités d'une alliance avec les anarchistes contre l'ennemi commun: le capitalisme. ${ }^{2}$

Il polémiqua avec tous ceux qui, suivant la doctrine anarchiste, négligeaient la lutte pour la démocratie politique, et tous ceux qui étaient teintés de nationalisme. Il était antimilitariste, et il recommanda aux ouvriers hongrois d'accorder une vigilance particulière à la politique extérieure de leur gouvernement. Ses principaux efforts ten-

1 Voir lettre de Frankel à Károly Farkas d'août 1872, in : Magda Aranyossi, Leo Frankel, Dietz, Berlin 1957, pp. 277-278.

2 János Jemnitz, "Adalékok Frankel Leó életéhez» (Contributions à la biographie de Leo Frankel), in: Párttörténeti Közlemények, 1964, no 4 ; compte rendu des séances du Congrès socialiste tenu à Gand du 9 au 16 septembre 1877. 
dirent toujours vers l'union de toutes les forces du mouvement ouvrier et vers la fin des années quatre-vingts il tenta de promouvoir la collaboration entre les différents groupes socialistes français. ${ }^{1}$ C'est pour la même raison qu'il participa à la fondation de la IIème Internationale à Paris en juillet 1889 .

Au debut des années quatre-vingt-dix, la comparaison de la situation en Belgique et en Hongrie lui permit de démontrer que la misère n'engendre pas directement la révolution et ne conduit pas à elle seule à la prise de conscience qui permet de résoudre les problèmes sociaux, mais que le seul moyen pour y parvenir est l'organisation et une direction compétente à la tête du mouvement ouvrier. Enfin, lorsque se réalisa en 1894 l'unité des forces socialistes en Hongrie, Frankel rappela que les ouvriers ne pouvaient s'émanciper que par leur propre prise de conscience, leurs propres forces, leur propre organisation.

Toute sa vie, Frankel fut un artisan acharné de l'unité ouvrière et un internationaliste convaincu. Sa dernière lettre, adressée à W. Liebknecht en mars 1896, témoigne de l'importance qu'il accordait à l'établissement d'une solidarité effective entre les prolétariats français et allemand. ${ }^{2}$ Mais, se référant à Marx et Engels, il pensait que le sort du mouvement ouvrier international se déciderait en Grande-Bretagne. Son testament est une profession de foi socialiste: «Ma seule volonté est d'être mis en terre enveloppé du drapeau rouge de la révolution prolétarienne à laquelle j'ai consacré la plus grande partie de ma vie et pour laquelle je suis encore prêt à toutes les souffrances et à tous les sacrifices. $\|^{3}$

Au lendemain de la chute de la Commune, dans un article paru dans le Vorbote en juillet-août 1871 , il fait remarquer que pour assurer sa survie et maintenir sa domination sur le prolétariat, la bourgeoisie a fait fi sans ambages des libertés démocratiques.Il ajoute que la Commune s'est créée de façon beaucoup plus démocratique que le gouvernement bourgeois issu de la révolution du 4 Septembre. Il revient sur ce sujet dans une lettre à Károly Farkas de 1872: il condamne les anarchistes qui n'apprécient pas à leur juste valeur les libertés démocratiques, mais il met aussi les socialistes hongrois en garde contre les illusions qu'ils pourraient se faire sur les démocrates radicaux. Pour lui la Commune confirme que le prolétariat est capable de prendre le pouvoir, mais enseigne aussi qu'il doit construire son propre parti.

Plus tard, en 1876-77, en Hongrie, il revient sans cesse dans ses articles sur les enseignements de la Commune. Il insiste sur l'impossi-

1 Lettre de Frankel à Engels de 1890.

2 Magda Aranyossi, op. cit., p. 384.

3 Ibid, p. 237. 
bilité de l'émancipation politique du prolétariat sans son émancipation sociale. Au cours des débats sur la Commune au Congrès de Gand en 1877, entre anarchistes et marxistes, Frankel s'oppose à Chalain, confirmant que la Commune avait été réellement démocratique. La même année, il commente longuement dans ses articles les projets d'expropriation de la Commune, et la fameuse loi limitant les traitements des fonctionnaires, mesures destinées à réaliser l'égalité sociale. ${ }^{1}$ D'une manière générale les écrits de Frankel sur la Commune peuvent être regroupés autour d'une idée principale: la nécessité de relier la revendication de l'émancipation sociale du prolétariat à une lutte constante pour la prise du pouvoir politique.

Dès son arrivée à Londres, Frankel devint le 22 août 1871 membre du Conseil général et le 26 septembre secrétaire responsable de la correspondance avec l'Autriche-Hongrie. ${ }^{2}$ C'est à la reconnaissance de ses mérites pendant la Commune qu'il doit sans doute ces élections, l'importance du rôle qu'il a joué aux Congrès de Londres et de La Haye, et même son élection, aux côtés d'Engels, à la commission d'enquête de l'A.I.T. Son passé de Communard le conduisit aussi à participer à l'organisation de l'émigration française en Angleterre. ${ }^{3}$ Puis, après une brève période d'activité dans les milieux allemand et autrichien, il revint en Hongrie au printemps 1876 où il devint immédiatement membre de la rédaction de l'Arbeiter-Wochen-Chronik (organe en langue allemande du mouvement socialiste hongrois). C'est également sa qualité d'ancien Communard qui lui valut son élection à la présidence du Congrès International de Gand, mais aussi son expulsion par les autorités belges. Il avait été auparavant arrêté et emprisonné pendant plusieurs mois en 1875 à Vienne.

En 1878 et 1880 , lors des tentatives de fondation d'un parti socialiste hongrois, ce fut à Frankel que les socialistes s'adressèrent pour l'élaboration du programme du parti. A la même époque il devint, dans la presse socialiste hongroise, le principal commentateur des événements internationaux, et le principal rédacteur d'articles théoriques. C'est à ces activités, mais tout autant à ses antécédents révolutionnaires, qu'il doit son arrestation et sa condamnation à la prison. Après sa libération en février 1883, il émigra à Vienne. Grâce à l'estime général dont il jouissait, il put s'y établir et de nombreux journaux socialistes sollicitèrent sa collaboration. C'est ainsi qu'au cours des années 1880-90, Frankel est souvent mentionné dans la correspondance d'Engels,

1 Munkás-Heti Krónika (Arbeiter-Wochen-Chronik), 18 mars 1877.

2 The General Council of the First International 1870-1871, Minutes, pp. 263, 282.

${ }^{3}$ Ch. Keller à Marx, 2 octobre 1871, Archives I.M.L. (Moscou), f. 1, op. 5, ed. chr. 2651. 
Bebel, ${ }^{1}$ Lafargue, ${ }^{2}$ W. Liebknecht, V. Adler et Lessner. Enfin à son retour en France en 1889, il renoua très vite avec les anciens Communards et les dirigeants socialistes français. ${ }^{3}$ Il devint administrateur de la revue marxiste Ere Nouvelle et collabora à l'Egalité et à la Bataille. Lorsqu'il tomba malade, ses camarades aidèrent sa famille qui vivait dans le dénuement. A sa mort, le 29 mars 1896, toute la presse socialiste lui rendit hommage. Outre la presse ouvrière hongroise, la presse socialiste française fit son éloge funèbre. Son ami et camarade de lutte F. Lessner rédigea pour la Neue Zeit un article de quatre pages qui ne parut pas. Lessner lui-même présenta ainsi le contenu de son article: "Leo Frankel, welcher grosse Opfer für die Arbeiterbewegung innerhalb 30 Jahren gebracht hat, verdient von allen anständigen Zeitungen in dieser Weise ein Denkmal zu setzen..) ${ }^{4}$

Traduit du hongrois

1 A. Bebel, lettre du 6 juin 1887 à sa femme, Archives I.M.L. (Moscou), f. 202, op. 1, ed. chr. 68 .

2 Correspondance Engels-Lafargue.

3 Lettres de Frankel à Engels.

4 Lettre de F. Lessner à Detloff, 5 avril 1896, Archives I.M.L. (Moscou), f. 178, op. 1 , ed. chr. $37 / 7$. 